\title{
IMMUNOHISTOCHEMICAL STUDY ON EXPRESSION OF C-MYC, P 53, C-ERBB-2 AND EPIDERMAL GROWTH FACTOR RECEPTOR IN HUMAN THYROID TUMORS
}

\author{
KenJi KASHIMA $^{1}$, Shigeo YOKOYAMA ${ }^{1}$, Iwao NAKAYAMA ${ }^{1}$ \\ AND SHIRo NOGUCHI ${ }^{2}$ \\ First Department of Pathology ${ }^{1}$, Medical College of Oita, Oita 879-55, \\ and Noguchi Thyroid Clinic and Hospital Foundation ${ }^{2}$, Oita 874
}

Received for publication August 26,1991 and in revised form September 19, 1991

\begin{abstract}
An immunohistochemical study was made of the expression of $c-m y c$ protein, $p$ 53, c-erbB-2 protein and epidermal growth factor receptor (EGF-R) in human normal thyroid and thyroid tumors including follicular adenoma and follicular, papillary, squamous cell, anaplastic and medullary carcinoma. Immunoreaction product for c-myc protein was located in the cytoplasm as well as nucleus of follicular cells in normal thyroid and neoplastic cells of all tumors. Semiquantitative analysis using serial dilutions of the antibody showed significant differences in immunoreactive cytoplasmic c-myc protein between normal thyroid and thyroid tumors. Immunoreaction product for $\mathrm{p} 53$ was noted in the cytoplasm of follicular cells in normal thyroid and neoplastic cells of all tumors, however, reaction product was absent in the nucleus for all cases of papillary and anaplastic carcinoma and 8 out of 10 cases of squamous cell carcinoma. On the other hand, normal thyroid and other types of thyroid tumor exhibited positive nuclear reaction for the antibody in about $50 \%$ of the cases. Immunoreaction product for c-erbB-2 protein and EGF-R was seen as either diffuse or granular deposits in the cytoplasm of the follicular cells in normal thyroid and neoplastic cells in all tumors, except for negative results in the immunostaining for EGF-R in normal thyroid. In immunostaining for these two antigens, thyroid tumor showed a significantly higher positivity than normal thyroid, and thyroid carcinoma showed a significantly higher incidence of positive cases than that of follicular adenoma, especially in immunostaining for EGF-R. These results show that cytoplamic c-myc protein, cerbB-2 protein and EGF-R are enhanced in many cases of thyroid tumor, and EGF-R tends to increase considerably in thyroid carcinoma. It is also suggested that nuclear p 53 might bear some relation to the differentiation of thyroid tumors.
\end{abstract}

It is well known that the prognosis of thyroid carcinoma is closely related to its histological differentiation. For example, the prognosis of anaplastic and squamous cell carcinoma of the thyroid are much worse than that for follicular, papillary or medullary carcinoma of the thyroid. Anaplastic and squamous cell carcinoma of the thyroid are believed to be primarily derived from follicular or papillary carcinoma (8), however, the reason why follicular and papillary carcinoma show differentiation into squamous cell or anaplastic carcinoma is still obscure.

In recent years many types of oncogenes have

Mailing address: Kenji Kashima, First Department of Pathology, Medical College of Oita, 1-1 Idaigaoka Hasamamachi, Oita-gun, Oita, 879-55 Japan been found and their amplification in several types of malignant tumors has also been reported (4). Expression of oncogenes, e.g., c- $m y c, \quad \mathrm{c}-e r b \mathrm{~B}, \mathrm{c}-e r b \mathrm{~B}-2$, is associated with prognosis of certain types of carcinoma $(15,18,21)$, therefore, oncogene products are considered to play some important biological role in malignant cells. The c-myc protein is localized mainly in the nucleus and is thought to regulate cell differentiation and division $(9,11)$. Epidermal growth factor receptor (EGF-R), a $170 \mathrm{k}$-dalton membrane protein which is composed of a partial amino acid sequence similar to that of the $\mathrm{v}-e r b \mathrm{~B}$ transforming protein of avian erythroblastosis virus, has tyrosine kinase activity in its internal domain (6). The product of c-erbB-2 is also a membrane protein with tyrosine kinase activity in its internal domain (2). Although the ligand for 
its external domain, which would be able to increase its tyrosine kinase activity, is still unknown, a point mutation of a residue in its transmembranous domain can increase gene activation (16).

These products bear some relation to the histological differentiation of malignant tumors, i.e., cerbB-2 protein is characterized by high expression in adenocarcinoma (20), and amplification of EGF-R occurs with a high incidence in squamous cell carcinoma (21). Therefore, it is worthwhile to investigate the correlation between the expression of these oncogenes and histological differentiation of the thyroid carcinomas.

On the other hand, p53 gene which had been considered to be an oncogene, is now recognized as an anti-oncogene (4), because p 53 can inhibit cell transformation and mutated p53 induces cell transformation $(7,19)$. Although quantitative alteration of $\mathrm{p} 53$ and immunohistochemical distribution of p 53 in thyroid tumors are interesting in view of anti-oncogene $\mathrm{p} 53$ function, there has been no report on this subject as far as we know.

In the present study, the expression of c-myc protein, EGF-R, c-erbB-2 protein and p 53 in human thyroid tumors including follicular adenoma and follicular, papillary, squamous cell, anaplastic and medullary carcinoma was investigated immunohistochemically. The expressions were estimated semiquantitatively by serially diluting the primary antibodies.

\section{MATERIALS AND METHODS}

Tissue preparations and immunostaining procedure

The materials used in this study consisted of 68 cases of thyroid obtained at surgery, which included 8 cases of normal thyroid surrounding follicular adenoma and 11 follicular adenomas, 10 follicular carcinomas, 13 papillary carcinomas, 10 squamous cell carcinomas, 9 anaplastic carcinomas and 7 medullary carcinomas. All materials was fixed with buffered formalin for $24 \mathrm{hr}$ and embedded in paraffin and cut at 4 $\mu \mathrm{m}$. The sections were preincubated for $15 \mathrm{~min}$ in normal rabbit or goat serum diluted $1: 10$. After blotting of excess serum, the sections were incubated in primary antibodies for $16 \mathrm{hr}$ at $4^{\circ} \mathrm{C}$ and followed by avidin-biotin complex method (10) (ABC kit, Nichirei Corporation, Tokyo, Japan). All sections were then treated with Tris-HCl buffer containing $0.02 \% 3,3^{\prime}$ diaminobenzidine tetrahydrochloride and $0.005 \%$ $\mathrm{H}_{2} \mathrm{O}_{2}$ for $5 \mathrm{~min}$. Nuclei were counterstained for 5 min with hematoxylin.

For semiquantitative analysis of the immunoreactivity, serial dilution of the primary antibodies was performed. Control sections incubated in normal mouse or rabbit IgG instead of the primary antibodies showed no non-specific staining.

\section{Primary antibodies}

All primary antibodies used in the present study were commercially available. Mouse monoclonal anti-c-myc protein (Oncogene Science Inc., New York, USA), anti-p 53 (Oncogene Science Inc.), and antiEGF-R (Cambridge Research Biochemicals Ltd., London, UK) antibodies and rabbit polyclonal anti-c-erbB2 protein antibody (Nichirei Corporation) were used at dilutions from $1: 20(5 \mu \mathrm{g} / \mathrm{ml})$ to $1: 320$ in the serial dilution test.

\section{Statistical evaluations}

The $\chi^{2}$ test or Fisher's exact probability test was applied for analyzing cases of positive incidence. Student's $t$ test was used for analyzing the results of the serial dilution test.

\section{RESULTS}

The results obtained from immunostaining using the primary antibodies diluted $1: 20$ are summarized

TABLE 1. Results of the Immunostainings for Products of Oncogene and Anti-oncogene

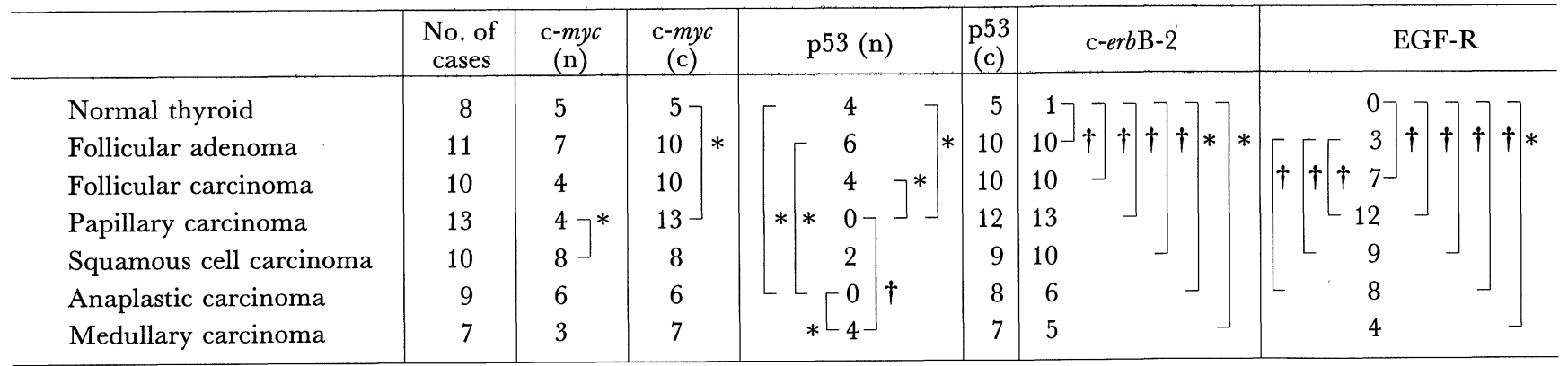

c-myc (n): nuclear c-myc protein, c-myc (c): cytoplasmic c-myc protein, p53 (n): nuclear p53, p53 (c): cytoplasmic p53, *: p $<0.05$,

$\dagger: \mathrm{p}<0.01$. 
in Table 1. The data of the semiquantitative analysis with serial dilutions of the primary antibodies are shown in Fig. 1.

Immunoreaction product for c-myc protein was
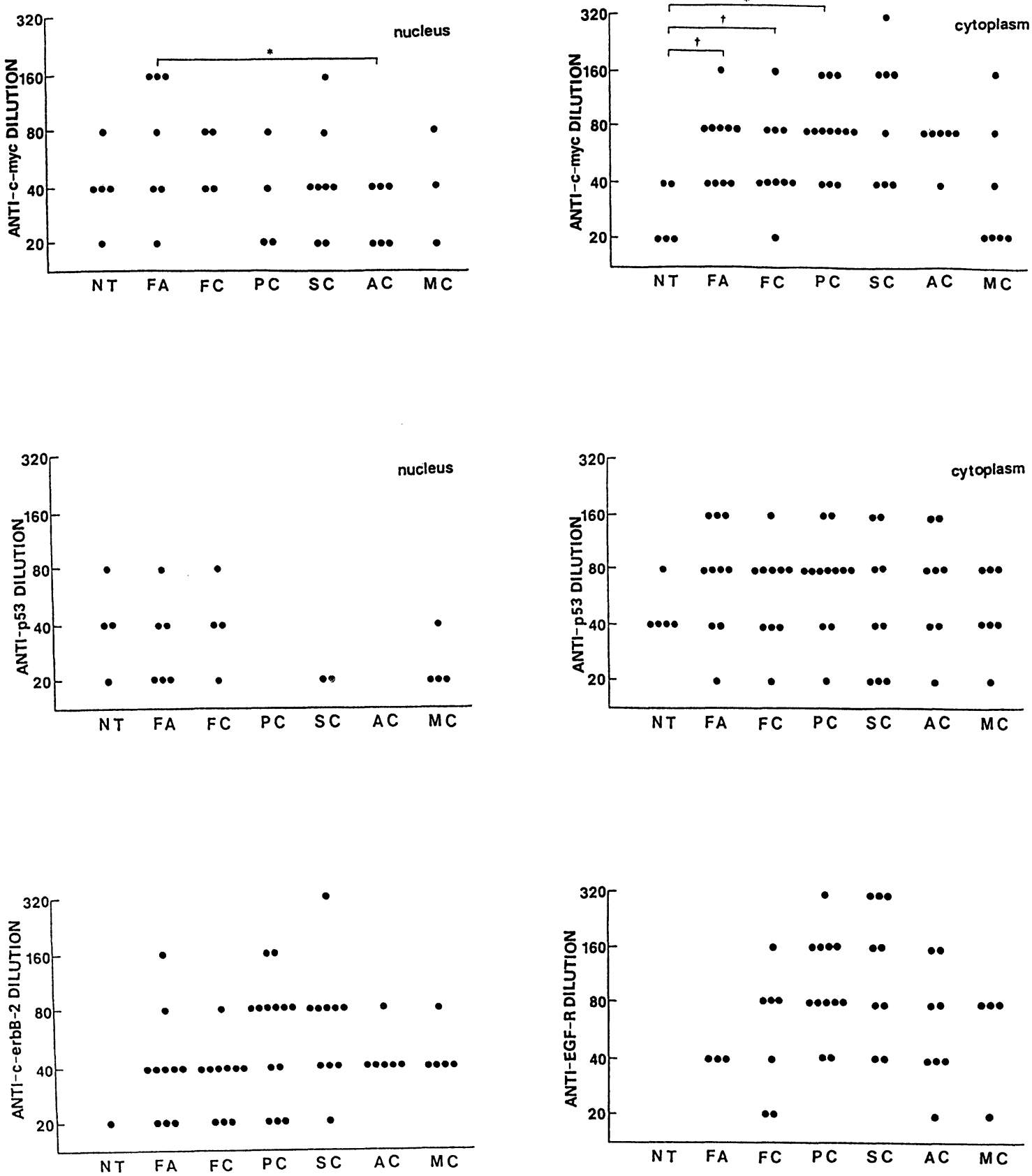

FIG. 1. Results of semiquantitative analysis of staining intensity by serial dilutions of primary antibodies. A dot (๑) indicates a case of positive immunostaining and a limit of dilution of the primary antibody for each case.

NT: normal thyroid, FA: follicular adenoma, FG: follicular carcinoma, PG: papillary carcinoma, SC: squamous cell carcinoma, AC: anaplastic carcinoma, MC: medullary carcinoma. ${ }^{*}: \mathrm{p}<0.05, \uparrow: \mathrm{p}<0.01$. 


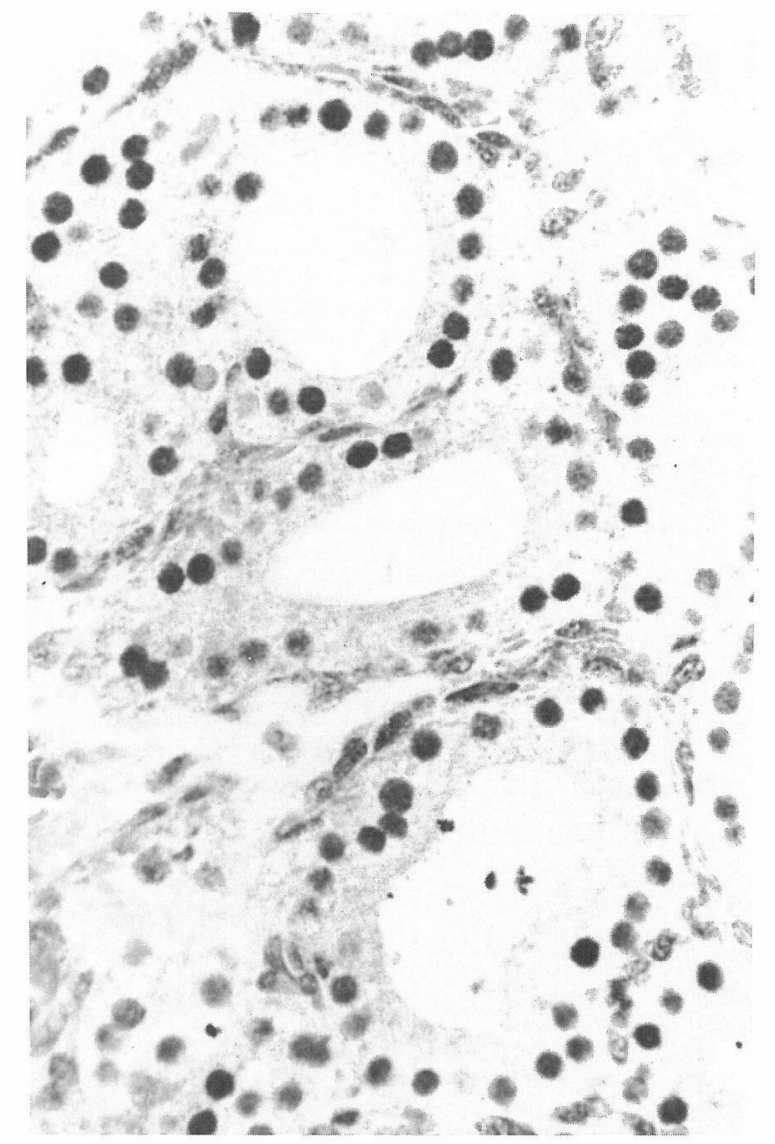

FIG. 2. A micrograph taken from follicular adenoma shows positive staining for nuclear c-myc protein. $\quad \times 350$

the reaction product differed somewhat from one tumor to another and from one area to another, even in the same section. Positive cases for nuclear c-myc protein were described with a significantly higher incidence in squamous cell carcinoma than in papillary carcinoma. However, the incidence for the immunoreactive nuclear c-myc protein did not differ significantly in the statistical analysis from normal thyroid to follicular adenoma and other types of thyroid carcinomas. Nevertheless, the dilution test of the primary antibody showed a significant difference only between follicular adenoma and anaplastic carcinoma, and demonstrated a higher content of the nuclear c-myc protein in the former tumor than in the latter one. Cytoplasmic c-myc protein was identified with high incidence in all types of thyroid tumor, and its positive ratio for papillary carcinoma was significantly higher than that of normal thyroid, although statistical analysis of positive cases was not significantly different among normal thyroid, follicular adenoma and other types of thyroid carcinoma. Ac-

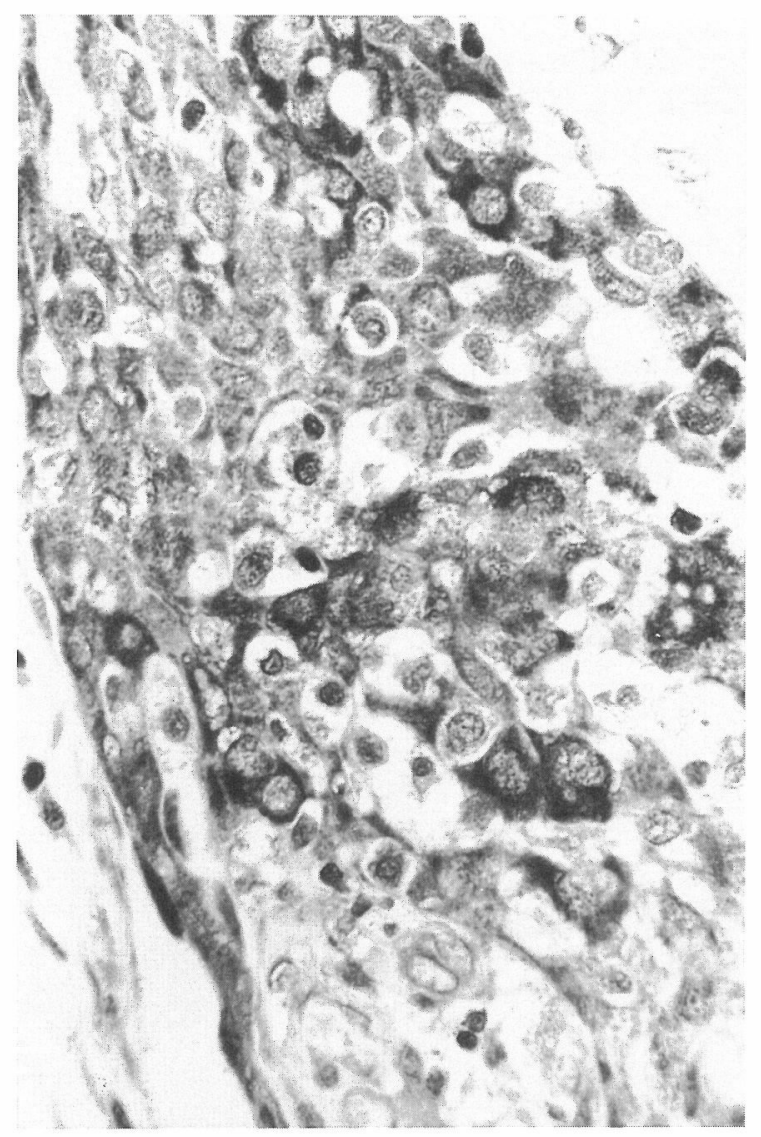

FIG. 3. Positive reaction product for c-myc protein in the cytoplasm. Squamous cell carcinoma. $\times 350$

cording to the semiquantitative analysis, the content of cytoplasmic c-myc protein was increased significantly in all thyroid neoplasms $(\mathrm{p}<0.05$ or $\mathrm{p}<0.01)$ except for medullary carcinoma of the thyroid, compared to that of normal thyroid.

With immunostaining for $\mathrm{p} 53$, the reaction product was present in the nucleus and cytoplasm as seen in immunostaining for c-myc protein (Figs. 4, 5). Interestingly, nuclear p 53 staining was not observed in any cases of papillary and anaplastic carcinoma, or 8 out of 10 cases of squamous cell carcinoma with both techniques of routine immunostaining and the dilution test, whereas normal thyroid, follicular adenoma, follicular carcinoma and medullary carcinoma had about a $50 \%$ positive ratio for imunoreactive nuclear p 53. On the other hand, cytoplasmic p 53 staining was present with high incidence in all types of thyroid tumor. However, normal thyroid, benign and all types of malignant neoplasms did not differ significantly in the ratio of positive cases or in the semiquantitative estimation. 


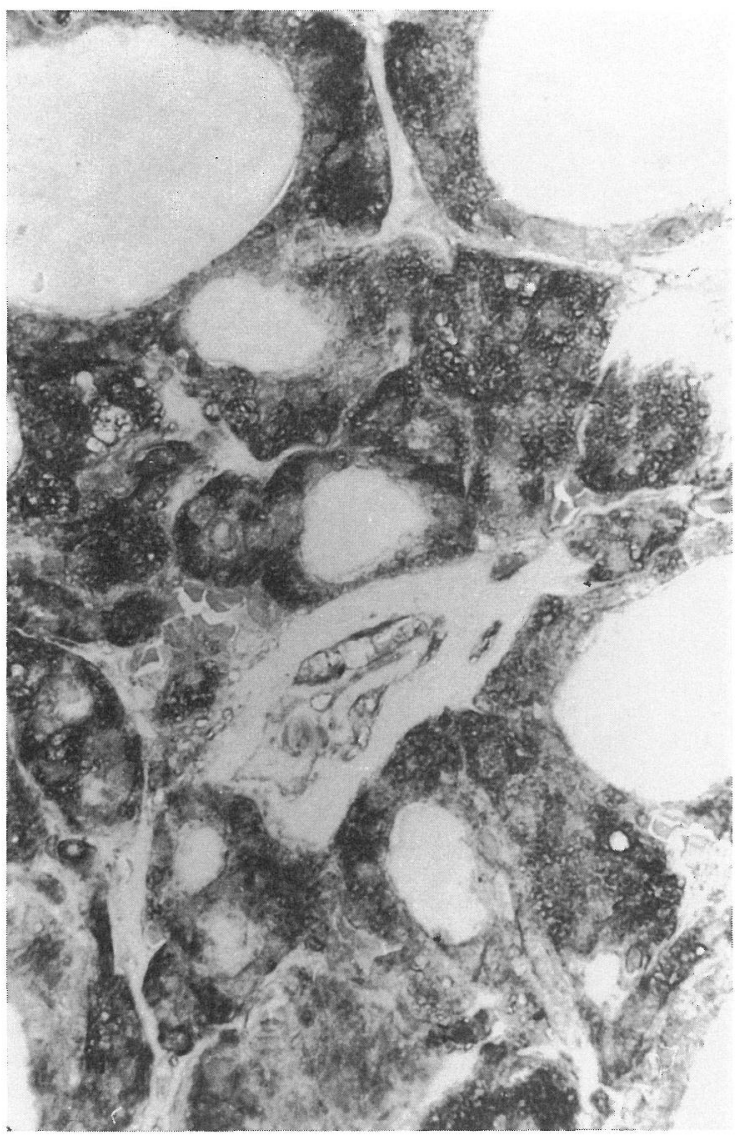

FIG. 4. Immunostaining for p53 is revealed as positive reaction product in the nucleus and cytoplasm. Follicular adenoma. $\times 350$

Using the anti-c-erbB-2 protein antibody, immunoreaction product showed intense expression throughout the entire cytoplasm (Fig. 6), nevertheless, it was expected to appear predominantly on the surface of the plasma membrane. The immunoreaction for anti-c-erbB-2 occurred with high incidence in all benign and malignant thyroid tumors, but only one out of 8 cases of normal thyroid was positive. Therefore, positivities of all types of thyroid tumor were significantly higher than that of normal thyroid. However, no quantitative difference of the c-erbB-2 protein among any type of the thyroid tumors was revealed by the serial dilution test of the primary antibody.

With immunostaining for EGF-R, diffuse reaction product was located predominantly in the cytoplasm of the thyroid tumors (Fig. 7); furthermore, granular deposits of the reaction product were also seen in focal areas of some cases of follicular, papillary and squamous cell carcinomas (Fig. 8). In contrast to

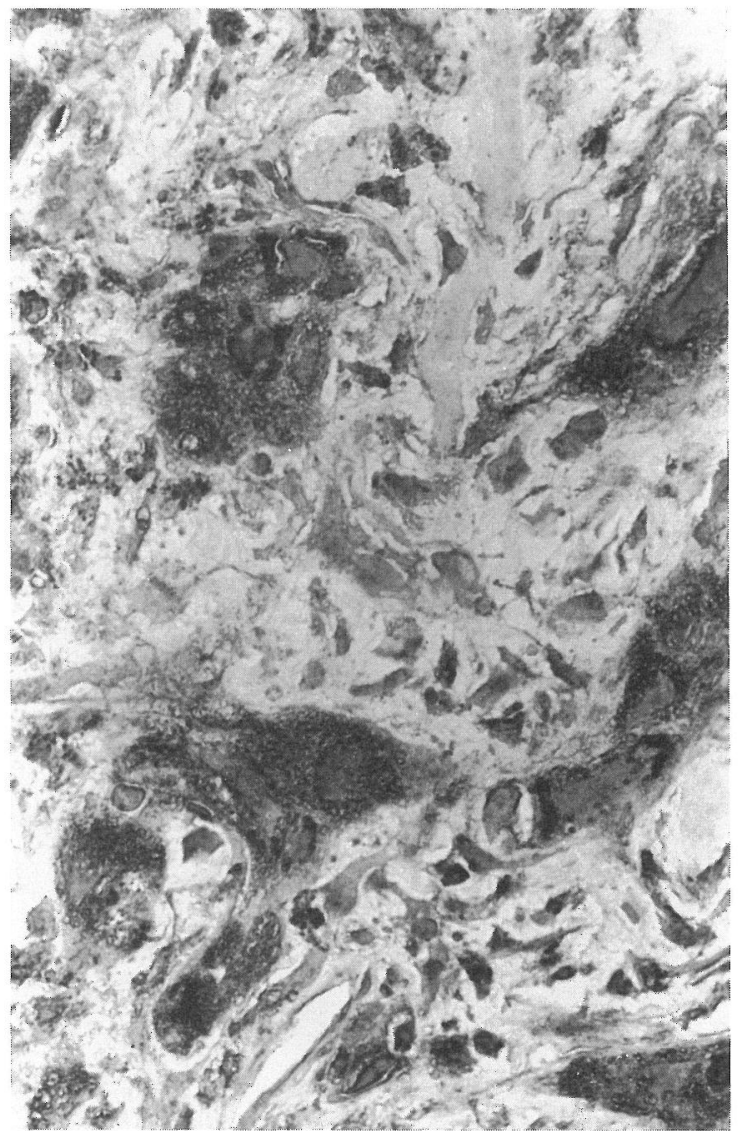

FIG. 5. Intense and diffuse reaction product for p53 in the cytoplasm. Anaplastic carcinoma. $\times 350$

high positivity for the immunoreactive EGF-R in thyroid carcinoma, it was relatively low in follicular adenoma (37.5\%) and negative in all cases of normal thyroid. The serial dilution test of the primary antibody revealed no quantitative differences in the expression of EGF-R among any type of thyroid carcinoma.

\section{DISGUSSION}

The c-myc gene encodes a nuclear phosphoprotein which has the ability for non-specific binding to DNA (4). It has been proved that enforced expression of the c-myc gene inhibits cell differentiation in vitro (9). Holt et al. reported that an oligomer complementary to cmyc mRNA inhibits proliferation of HL60 promyelocytic cells and induces differentiation (11). In the present study, the expression of cytoplasmic c-myc was enhanced more intensively in the tumors than in normal thyroid. This enhancement seems not to con- 


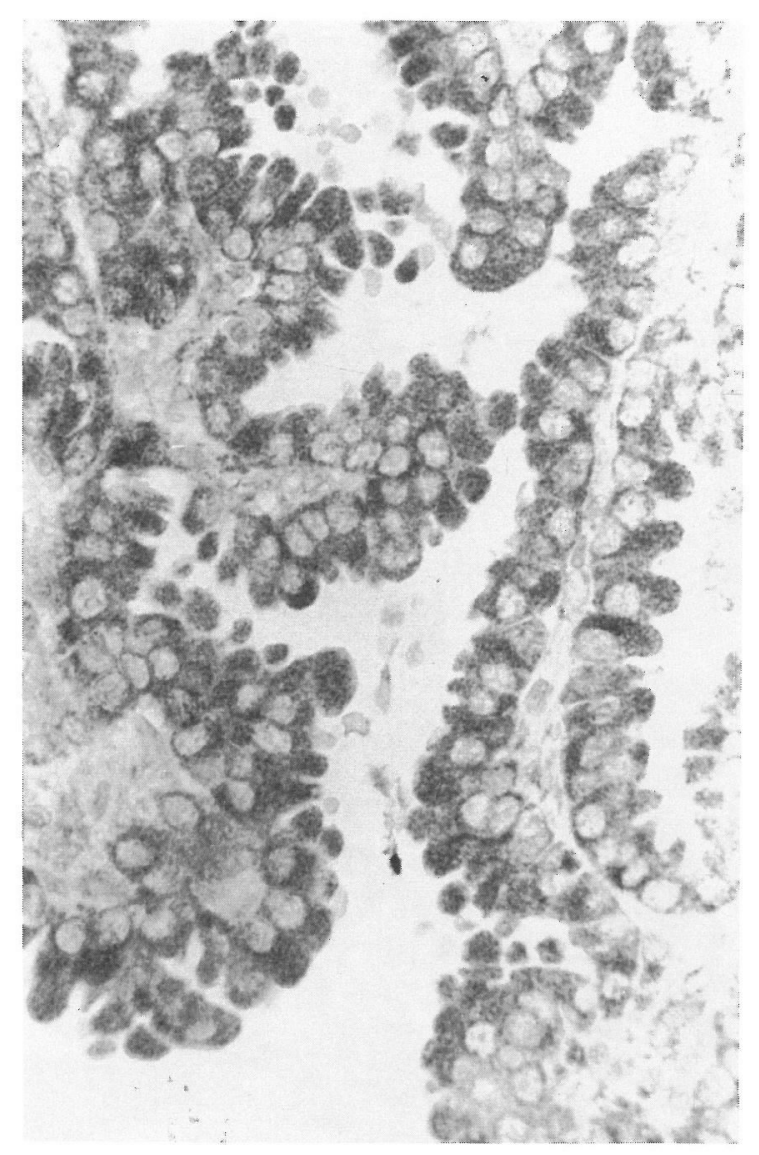

Fig. 6. Diffuse reaction product for c-erbB-2 protein is demonstrated in the cytoplasm. Papillary carcinoma. $\times 350$

tradict the role of the c-myc protein in inducing cell proliferation.

Chi and William (4) have shown that immunofluorescence of normal c-myc protein is located in the nucleus, but a mutated c-myc protein with amino acids 262 to 372 deleted exhibits a diffuse cytoplasmic staining. This supports the notion that signals within the normal c-myc gene determine nuclear localization of its products, and cytoplasmic localization of c-myc protein has the possibility of reflecting a mutation in the c-myc gene. Accumulation of cytoplasmic c-myc protein in thyroid tumors observed in the present study is considered to be consistent with the above described possibility. The biological role of the cytoplasmic c-myc protein is still unknown, however, it is interesting that the cytoplasmic c-myc protein was higher in thyroid tumors than in normal thyroid in spite of no correlation of the expression of nuclear cmyc protein between them. This finding makes us believe that there is an association of the cytoplasmic

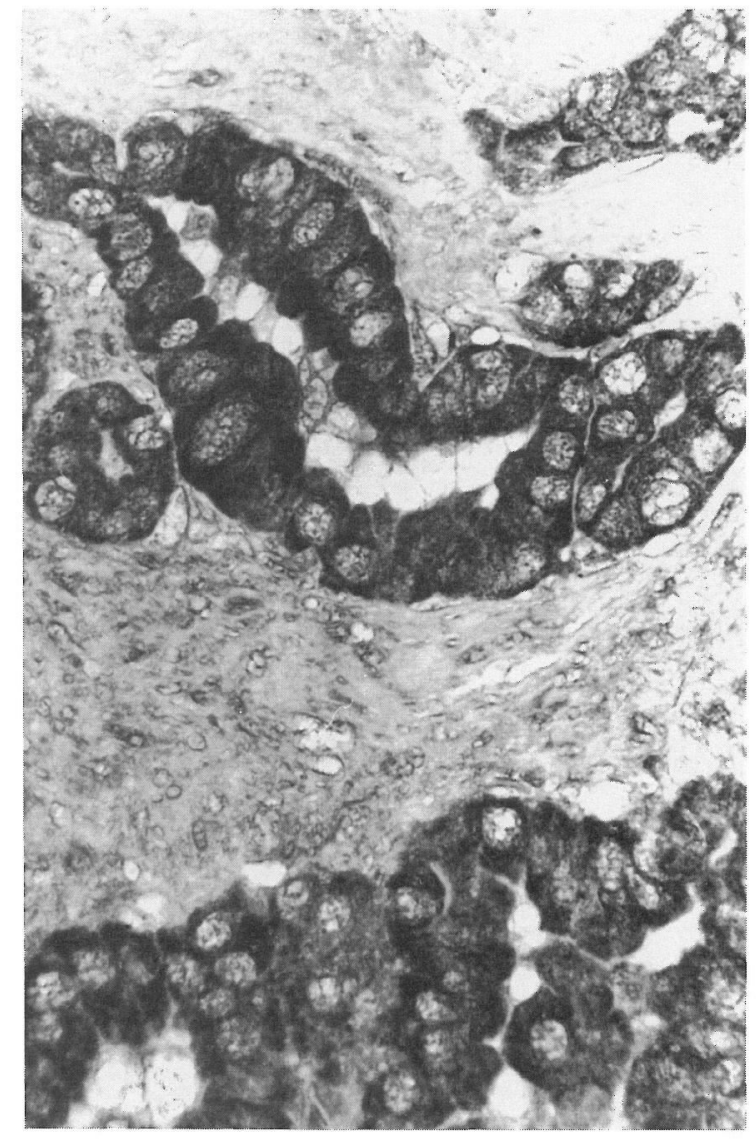

FIG. 7. Intense and diffuse reaction product for EGF-R in the cytoplasm. Papillary carcinoma. $\times 350$

protein with some biological behavior of thyroid tumors.

Immunoreaction product for p 53 was observed not only in the nucleus but also in the cytoplasm of the follicular cells in normal thyroid and neoplastic cells in some tumors. The $\mathrm{p} 53$ is stabilized by forming a complex with some other proteins, although the half life of p 53 is only $6-30$ min without the complex formation (14). It is supposed, therefore, that differently localized p 53 may bind to another protein and play another role in the cell. In the present study, all cases of papillary and anaplastic carcinoma and most cases of squamous cell carcinoma showed no nuclear p 53, whereas it was present in the nucleus in about half of the cases of the other types of tumor and normal thyroid. No or low expression of nuclear p 53 in papillary, squamous cell and anaplastic carcinoma losing original follicular or papillary structure, leads us to speculate that the nuclear p 53 might be associated with differentiation of thyroid tumors. 


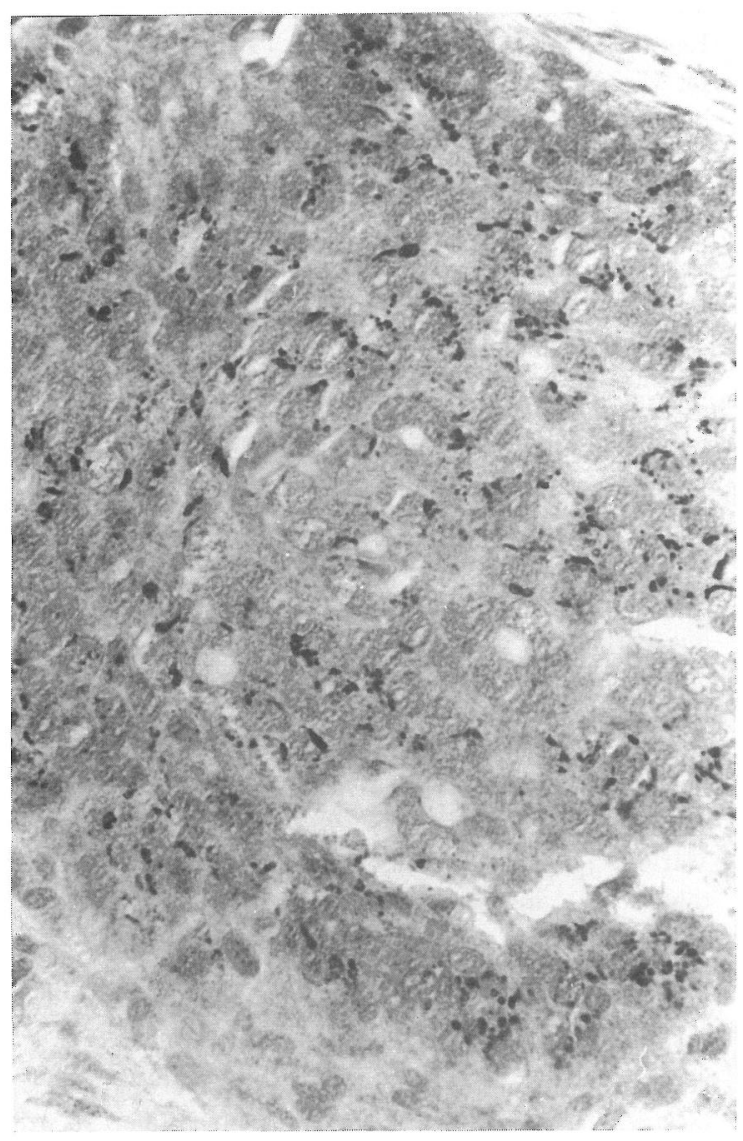

FIG. 8. Granular deposits of reaction product for EGF-R are seen in the cytoplasm. Squamous cell carcinoma. $\times 350$

It was reported that colon cancer (3), lung cancer (17) and chronic myelocytic leukemia (1) are frequently lacking the non-mutated p 53 gene whose product is now considered to behave as a tumor suppressor. No or low expression of nuclear p53 in papillary, anaplastic and squamous cell carcinoma of the thyroid suggests that the lack of non-mutated p 53 gene might happen in these types of thyroid carcinoma, although it must be clarified whether non-mutated p 53 gene was present or not in thyroid carcinomas.

The intracellular domain of c-erbB-2 protein as well as EGF-R has tyrosine kinase activity which may play an important role in the transforming activity of c-erbB-2 (16). The tyrosine kinase activity is elevated in the mutated c-erbB-2 protein, and even the overexpression of c-erbB-2 protein without the mutation of ${ }^{659} \mathrm{Val} \rightarrow{ }^{659} \mathrm{Glu}$ in transmembranous domain can induce transformation (5). Application of polymerase chain reaction showed no mutation in the c-erbB-2 gene in human breast carcinoma (13); it is supposed, therefore, that c-erbB-2 protein is associated with the transformation mainly because of its overexpression in vivo. Immunostaining for $c-e r b \mathrm{~B}-2$ protein and semiquantitative analysis for c-erbB-2 protein are considered to be useful in investigating the biological role of c-erbB-2 protein. However, the immunostaining for c-erbB-2 showed intense reaction product in both benign and malignant tumors but no reaction in normal thyroid except for one case, thus, c-erbB-2 protein seems to be associated with some biological role in thyroid tumors irrespective of their malignant potential.

Immunostaining for EGF-R showed more enhanced positivity in all types of thyroid carcinoma than in follicular adenomas. However, there was no significant difference in the staining intensity between squamous cell carcinoma and other carcinomas, even though EGF-R was expected to be overexpressed in squamous cell carcinoma. We have already reported that EGF-R was expressed with high incidence in invasive carcinoma of the thyroid (12). It is suggested, therefore, that EGF-R may be associated with proliferation of thyroid carcinoma regardless of its histological differentiation.

Granular deposits of reaction product for EGF-R observed in follicular and papillary carcinoma of the thyroid in our previous report (12), were seen also in squamous cell carcinoma in the present study. Interestingly, the distribution of the granular deposits of the reaction product was restricted to part of the tissues and to some cases of thyroid carcinoma. The pathogenesis of the granular deposits of the reaction product for EGF-R in the neoplastic cells is expected to be clarified by further study.

The present study indicates that c-erbB-2 and cmyc protein are overexpressed in the cytoplasm of thyroid neoplasms regardless of histological type in spite of an enhanced expression of EGF-R in malignant thyroid tumors, and c-myc gene has the possibility for mutation in thyroid neoplasms, because of enhanced expression of c-myc protein in the cytoplasm of most of thyroid neoplasms. It is also indicated that the expression of $\mathrm{p} 53$ in the nucleus of thyroid neoplasms may be associated with their histological differentiation which is a major prognostic factor for thyroid carcinomas.

\section{REFERENCES}

1. Ahuja, H., Bar-Eli, M., Advani, S. H., Benchimol, S. and Cline, M. J.: Alterations in the p 53 gene and the clonal evolution of the blast crisis of chronic myelocytic leukemia. Proc. Natl. Acad. Sci. USA 86; 6783-6787, 
1989.

2. Akiyama, T., Sudo, G., Ogawara, H., Toyoshima, K. and Yamamoto, T.: The product of the human c-erbB-2 gene: A 185-kilodalton glycoprotein with tyrosine kinase activity. Science 232; 1644-1646, 1986.

3. Baker, S. J., Fearon, E. R., Nigro, J. M., Hamilton, S. R., Preisinger, A. C., Jessup, J. M., vanTuinen, P., Ledbetter, D. H., Barker, D. F., Nakamura, Y., White, R. and Vogelstein, B.: Chromosome 17 deletions and p53 gene mutations in colorectal carcinomas. Science 244; 217-221, 1989.

4. Burck, K. B., Liu, E. T. and Larrick, J. W.: Oncogenes: An introduction to the concept of cancer genes. Springer-Verlag, New York, 1988.

5. DiFiore, P. P., Pierce, J. H., Kraus, M. H., Segatto, O., King, C. R. and Aaronson, S. A.: erbB-2 is a potent oncogene when overexpressed in NIH/3T3 cells. Science 237; 178-182, 1987.

6. Downward, J., Yarden, Y., Mayes, E., Scrace, G., Totty, N., Stockwell, P., Ullrich, A., Schlessinger, J. and Waterfield, M. D.: Close similarity of epidermal growth factor receptor and $\mathrm{v}$-erbB oncogene protein sequences. Nature 307; 521-527, 1984.

7. Finlay, G. A., Hinds, P. W. and Levine, A. J.: The p 53 proto-oncogene can act as a suppressor of transformation. Cell 57; 1083-1093, 1989.

8. Fisher, E. R., Gregorio, R., Shoemaker, R., Horvat, B. and Hubay, C.: The derivation of so-called "giant-cell" and "spindle-cell" undifferentiated thyroidal neoplasms. Am. J. Clin. Pathol. 61; 680-689, 1974.

9. Freytag, S. O.: Enforced expression of the c-myc oncogene inhibits cell differentiation by precluding entry into a distinct predifferentiation state in $\mathrm{G}_{0} / \mathrm{G}_{1}$. Mol. Cell. Biol. 8; 1614-1624, 1988.

10. Guesdon, J. L., Ternynck, T. and Avrameas, S.: The use of avidin-biotin interaction in immunoenzymatic technique. J. Histochem. Cytochem. 27; 1131-1139, 1979.

11. Holt, J. T., Redner, R. L. and Nienhuis, A. W.: An oligomer complementary to c-myc mRNA promyelocytic cells and induces differentiation. Mol. Cell. Biol. 8; 963973, 1988.

12. Kashima, K., Yokoyama, S., Nakayama, I. and Noguchi, S.: Expression of epidermal growth factor receptor in human benign and malignant thyroid les- ions. J. Jpn. Soc. Cancer Ther. 26; 21-31, 1991.

13. Lemoine, N. R., Staddon, S., Dickson, C., Barnes, D. M. and Gullick, W. J.: Absence of activity transmembrane mutations in the c-erbB-2 proto-oncogene in human breast cancer. Oncogene 5; 237-239, 1990.

14. Oren, M., Maltzman, W. and Levine, A. J.: Posttranslational regulation of the $54 \mathrm{~K}$ cellular tumor antigen in normal and transformed cells. Mol. Cell. Biol. 1; 101$110,1981$.

15. Slamon, D. J., Clark, G. M., Wong, S. G., Levin, W. J., Ullrich, A. and McGuire, W. L.: Human breast cancer: Correlation of relapse and survival with amplification of the HER-2/neu oncogene. Science 235; 177-182, 1987.

16. Segatto, O., King, R., Pierce, J. H., DiFiore, P. P. and Aaronson, S. A.: Different structural alterations upregulate in vitro tyrosine kinase activity and transforming potency of the erbB-2 gene. Mol. Cell. Biol. 8; 55705574, 1988.

17. Takahashi, T., Nau, M. M., Chiba, I., Birrer, M. J., Rosenberg, R. K., Vinocour, M., Levitt, M., Pass, H., Gazdar, A. F. and Minna, J. D.: p 53: A frequent target for genetic abnormalities in lung cancer. Science 246; 491-494, 1989.

18. Varley, J. M., Swallow, J. E., Brammer, W. J., Whittaker, J. L. and Walker, R. A.: Alterations to either cerbB-2(neu) or c-myc proto-oncogenes in breast carcinomas correlate with poor short-term prognosis. Oncogene 1 ; 423-430, 1987.

19. Wolf, D., Admon, S., Oren, M. and Rotter, V.: Abelson murine leukemia virus-transformed cells that lack p 53 protein synthesis express aberrant p 53 mRNA species. Mol. Cell. Biol. 4; 552-558, 1984.

20. Yamada, Y., Yoshimoto, M., Murayama, Y., Ebuchi, M., Mori, S., Yamamoto, T., Sugano, H. and Toyoshima, K.: Association of elevated expression of the c-erbB-2 protein with spread of breast cancer. Jpn. J. Cancer Res. 80; 1192-1198, 1989.

21. Yamamoto, T., Kamata, N., Kawano, H., Shimizu, S., Kuroki, T., Toyoshima, K., Rikimaru, K., Nomura, N., Ishizaki, R., Pastan, I., Gamou, S. and Shimizu, N.: High incidence of amplification of the epidermal growth factor receptor gene in human squamous carcinoma cell lines. Cancer Res. 46; 414-416, 1986. 